\title{
Szczelinowanie gazowe gazonośnych pokładów węgla kamiennego - badania poligonowe
}

\begin{abstract}
Celem prezentowanych badań jest próba odpowiedzi na pytanie, czy metoda stymulacji przypływu medium do odwiertu, znana z zastosowań w przemyśle naftowym, może zostać wykorzystana w stymulacji gazonośnych pokładów węgla kamiennego. Rozważana metoda, oparta na szczelinowaniu gazowym z użyciem materiałów wysokoenergetycznych (propelantów), polega na niedetonacyjnym wykonaniu sieci spękań calizny skalnej w postaci kilku radialnych szczelin $\mathrm{w}$ strefie otworu udostępniającego. W artykule przedstawiono rezultaty pierwszych prób strzałowych na wybranych próbkach węgla kamiennego. W tym celu przygotowano stalowo-betonowe modele zbliżające warunki testów do otworopodobnych, opracowano metodykę badawczą służącą oszacowaniu efektów eksperymentów oraz przeprowadzono serię testów strzałowych na poligonie doświadczalnym. Efekty prób szczelinowania próbek węglowych z wykorzystaniem propelantów przedstawiono graficznie w formie rentgenogramów.
\end{abstract}

Słowa kluczowe: propelanty, szczelinowanie gazowe, metan z węgla.

\section{Gas fracturing of coalbed methane strata - field testing}

The research presented in the work is an attempt to respond to the question, of whether the medium inflow stimulation method, already known from oil and gas industry applications, can be useful for stimulation of coalbed methane strata. The method in question, is based on gas fracturing with the use of high-energetic materials (propellants), it consists in non-explosive performance of rock matrix fracture network, in the form of several radial fractures within near-bore zone of borehole. The work presents results of initial shot attempts done on selected samples of hard coal. To this end several steel and concrete research models have been prepared, making the test conditions closer to simulated borehole conditions. A research methodology, serving estimation of experimental results was developed, and several shot test on an experimental fireground were executed. The effects of hard coal samples fracturing tests using propellants, are shown in graphical form, as X-ray images.

Key words: propellants, gas fracturing, coalbed methane.

\section{Wprowadzenie}

Największe udokumentowane zasoby metanu zalegającego w pokładach węgla kamiennego w Polsce występują w Górnośląskim Zagłębiu Węglowym [11]. Geologiczne złoża metanu na tym obszarze szacowane są na poziomie $250 \mathrm{mld} \mathrm{m}^{3}$. Zasoby bilansowe metanu wynoszą $95 \mathrm{mld} \mathrm{m}^{3}$, w tym z obszarów kopalń - 29,8 mld $\mathrm{m}^{3}$ [10]. Są to znaczne ilości surowca, którym należy się zainteresować w kontekście pozyskania i jego bezpiecznej eksploatacji. Jednak, z uwagi na bardzo niską przepuszczalność formacji węglowej, taką akumulację węglowodorów możemy nazwać złożem niekonwencjonalnym, wymagającym szczególnego sposobu udostępnienia.
Najbardziej rozpowszechnioną metodą oddziaływania na gazonośny pokład węgla w kontekście pozyskania metanu jest zabieg obniżenia ciśnienia w złożu przez odprężenie górotworu, spowodowane odwodnieniem pokładów węgla. Po obniżeniu ciśnienia w górotworze do wartości izotermy sorpcji następuje proces uwolnienia zaabsorbowanego metanu [5]. Znikoma przepuszczalność skały węglowej wymusza jednak poszukiwanie dodatkowych, bardziej efektywnych metod stymulacji pokładów węgla umożliwiających przepływ uwolnionego metanu w złożu. Odpowiedzią na tak postawiony problem może być zastosowanie technologii szczelinowania gazowego pokładów węgla z użyciem propelantów. 


\section{Metoda badawcza}

Zaproponowana metoda badawcza polega na wizualnej ocenie spękań próbki węgla kamiennego wywołanych odpaleniem ładunku propelantowego $\mathrm{w}$ warunkach poligonowych. Próbki węgla po zabiegu szczelinowania gazowego zostaną poddane ocenie wizualnej natychmiast po wykonaniu testu strzałowego oraz później na podstawie rentgenogramów pochodzących ze skanowania tomografem komputerowym. Dodatkowe informacje na temat przebiegu testów szczelinowania w warunkach laboratoryjnych uzyskiwane są za pomocą układu mierzącego i rejestrującego przebieg zmian ciśnieniowych, na podstawie których odtwarzany jest profil narastania ciśnienia.

Celem testów strzałowych było wykonanie prób szczelinowania gazowego próbek węgla kamiennego przy użyciu ładunków propelantowych i zachowaniu warunków badania zbliżonych jak najbardziej do rzeczywistych. Prace z użyciem materiałów wysokoenergetycznych prowadzono na poligonie strzałowym w specjalnie zaprojektowanych i wykonanych stanowiskach betonowo-stalowych. Schemat układu badawczego przedstawiono na rysunku 1. Próbkę węgla kamiennego z odwierconym otworem na ładunek propelantowy umieszczano w plastikowym pojemniku o pojemności 65 litrów i zalewa- no betonem, który po wysezonowaniu pełnił rolę stabilizacyjną i przeciwdziałał całkowitemu zdefragmentowaniu węgla. W górnej części modelu badawczego usytuowano stalową rurkę, przez którą osadzono ładunek propelantowy w węglu i wyprowadzono na zewnątrz przewody elektryczne linii strzałowej. Przepust prądowy sporządzono przy pomocy świecy samochodowej umieszczonej w szczytowej części rurki. Tuż poniżej wykonano prostopadłą kryzę pomiarową, do której wkręcono piezoelektryczny przetwornik ciśnienia.
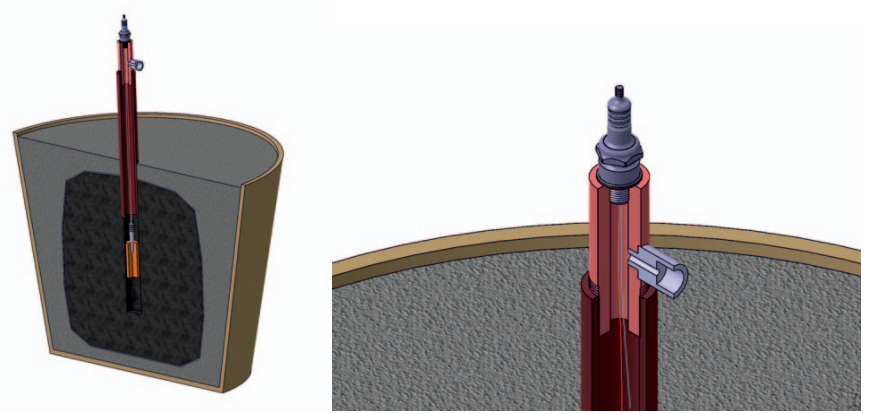

Rys. 1. Schemat betonowo-stalowego układu badawczego wykorzystanego do prób szczelinowania gazowego na poligonie strzałowym

\section{Przygotowanie ładunków propelantowych do testów strzałowych}

Badania strzałowe realizowano przy użyciu ładunków propelantowych składających się z mieszanki rodzimych paliw prochowych typu Szafir i Szmaragd. Ładunki prochowe otrzymały finalny cylindryczny kształt na skutek matrycowego zaprasowania pod prasą hydrauliczną. W górnej części ładunku nawiercono otwór, w którym umieszczono zapłonnik elektryczny. Całość zabezpieczono pod względem wodoszczelności płaszczem termokurczliwym. Widok paliwa, fazy przygotowawczej i końcowy kształt ładunku zamieszczono na rysunku 2.

Podstawowe dane dotyczące ładunków propelantowych przygotowanych na potrzeby prób strzałowych szczelinowania próbek węgla kamiennego zawarto w tablicy 1.

Tablica 1. Charakterystyka ładunków propelantowych obejmująca masę próbki, wysokość, gęstość i objętość paliwa

\begin{tabular}{|c|c|c|c|}
\hline$m[\mathrm{~g}]$ & $h[\mathrm{~mm}]$ & $\rho\left[\mathrm{g} / \mathrm{cm}^{3}\right]$ & $V\left[\mathrm{~cm}^{3}\right]$ \\
\hline 60,5 & 99,75 & 1,46 & 41,0 \\
\hline 61,6 & 94,53 & 1,57 & 39,2 \\
\hline 62,2 & 98,40 & 1,52 & 49,9 \\
\hline
\end{tabular}
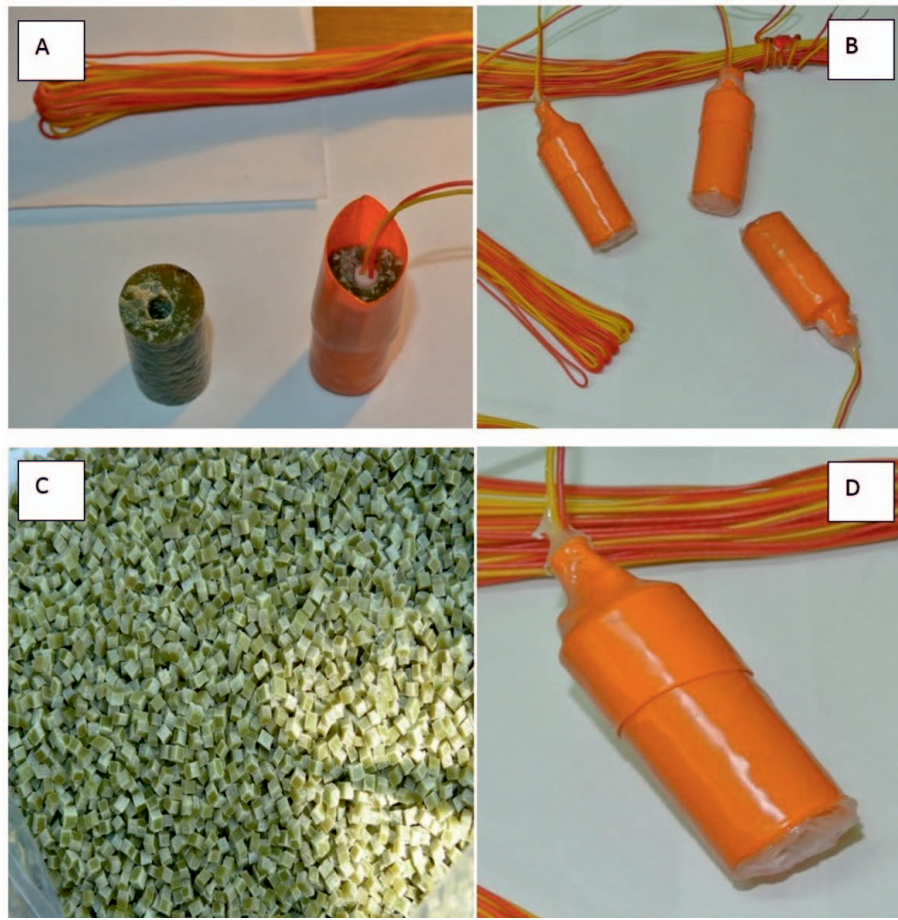

Rys. 2. Przygotowanie ładunków propelantowych do prób poligonowych: A - zaprasowany granulat paliwa typu Szafir/ Szmaragd z wykonanym otworem pod układ inicjujący,

$\mathrm{B}$ - zaprasowane ładunki propelantowe uzbrojone i zabezpieczone przed zawilgoceniem, $\mathrm{C}$ - granulat paliwa prochowego Szafir, D - pojedynczy ładunek propelantowy 


\section{Cześć eksperymentalna - badania strzałowe}

Na przygotowanych modelach betonowo-stalowych przeprowadzono $\mathrm{w}$ warunkach otwartego poligonu trzy testy strzałowe polegające na odpaleniu ładunku propelantowego w otoczonej betonem bryle węgla kamiennego. Efekty każdego z testów określono na podstawie: obserwacji wizualnej spękań, oceny wizualnej rentgenogramów komputerowych oraz zarejestrowanych profili narastania ciśnienia.

\section{Test strzałowy pierwszy}

Serię eksperymentów strzałowych otwiera test nr 1, polegający na odpaleniu w bryle węgla ładunku propelantowego o masie $60,5 \mathrm{~g}$. Betonowo-stalowy model strzałowy przetransportowano na poligon i przystąpiono do prac przygotowawczych polegających na: 1) uzupełnieniu wodą, jako medium nieściśliwym wolnej przestrzeni w rurze stalowej, 2) zapuszczeniu ładunku propelantowego do wnętrza modelu strzałowego, 3) zaślepieniu rury stalowej głowicą $\mathrm{z}$ króćcem pomiarowym przepustem prądowym linii strzałowej. Profil narastania ciśnienia w trakcie testu zarejestrowano za pomocą piezoelektrycznego przetwornika ciśnienia i oscyloskopu. W formie graficznej został on zaprezentowany na rysunku 3.

Zarejestrowany pik początkowy ciśnienia $P_{z}^{(1)}=3,89 \mathrm{MPa}$ $\mathrm{w}$ momencie czasowym $t_{z}^{(1)}=0,86 \mathrm{~s}$ pochodzi od zainicjowania zapłonnika, który w dalszej kolejności pobudza do zapłonu właściwy ładunek propelantowy. Po czasie $t_{\max }^{(1)}=0,32 \mathrm{~s}$ ciśnienie spalania propelantu osiąga wartość maksymalną, równą $P_{\max }^{(1)}=4,47 \mathrm{MPa}$. Od tego momentu następuje łagodny spadek ciśnienia gazów w badanym układzie, aż do całkowitej jego relaksacji $\mathrm{w}$ chwili czasowej $t_{\text {kon }}^{(1)}=1,13 \mathrm{~s}$, co spowodowane zostało rozszczelnieniem modelu badawczego.

Liczne spękania i uszkodzenia części cementowej modelu ułatwiły wydobycie badanej próbki węgla z płaszcza stabilizującego, po czym poddano ją skanowaniu rentgenowskim tomografem komputerowym w celu potwierdzenia powstałych szczelin bądź wykluczenia takiego efektu. Wybrane rentgenogramy próbki nr 1 przedstawiono na rysunku 4.

Uzyskany efekt skanowania tomografem komputerowym ma dwojaką naturę. Jeden rezultat to seria rentgenogramów pozwalająca prezentować badany obiekt w formie graficznej na płaszczyźnie tnącej w każdej z osi kartezjańskiego układu współrzędnych. Drugim efektem jest przyporządkowanie każde-

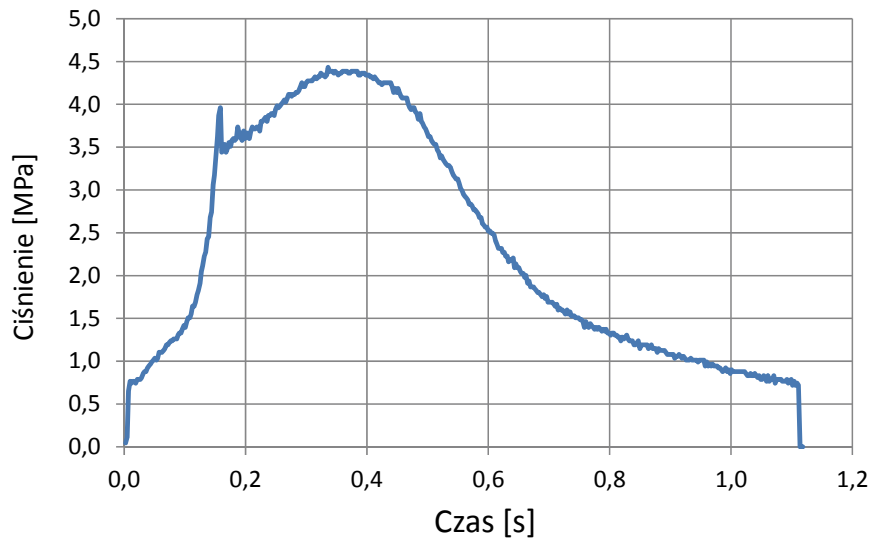

Rys. 3. Profil narastania ciśnienia w eksperymencie strzałowym nr 1

mu elementowi badanej przestrzeni konkretnej liczby w skali Hounsfielda (HU) odpowiadającej wskaźnikowi osłabienia radiologicznego w danym punkcie. Analizując rentgenogramy z pierwszego testu, można zaobserwować powstanie jednej wyraźnej szczeliny zlokalizowanej z lewej strony próbki, rozciągającej się ukośnie od nawierconego kanału centralnego do krańca bryły. $Z$ rentgenogramów odczytano średnią długość szczeliny, która oscylowała w przedziale $8,1 \div 12,7 \mathrm{~cm}$. Zarejestrowane dla tych punktów przestrzeni stopnie Hounsfielda (HU) silnie polaryzowały wartości odczytywane w szczelinie i w jej bezpośrednim sąsiedztwie, co jest wywołane dużą zmianą współczynnika osłabienia radiologicznego. Odczytane wartości w skali (HU) dla dowolnych arbitralnie wybranych punktów calizny bryły węglowej zamykały się w przedziale $131 \div 244$ (HU), a w miejscach, które według rentgenogramów wskazywałyby na powstanie szczelin, stopnie (HU) przybierały wartości ujemne -90 do -50 (HU).
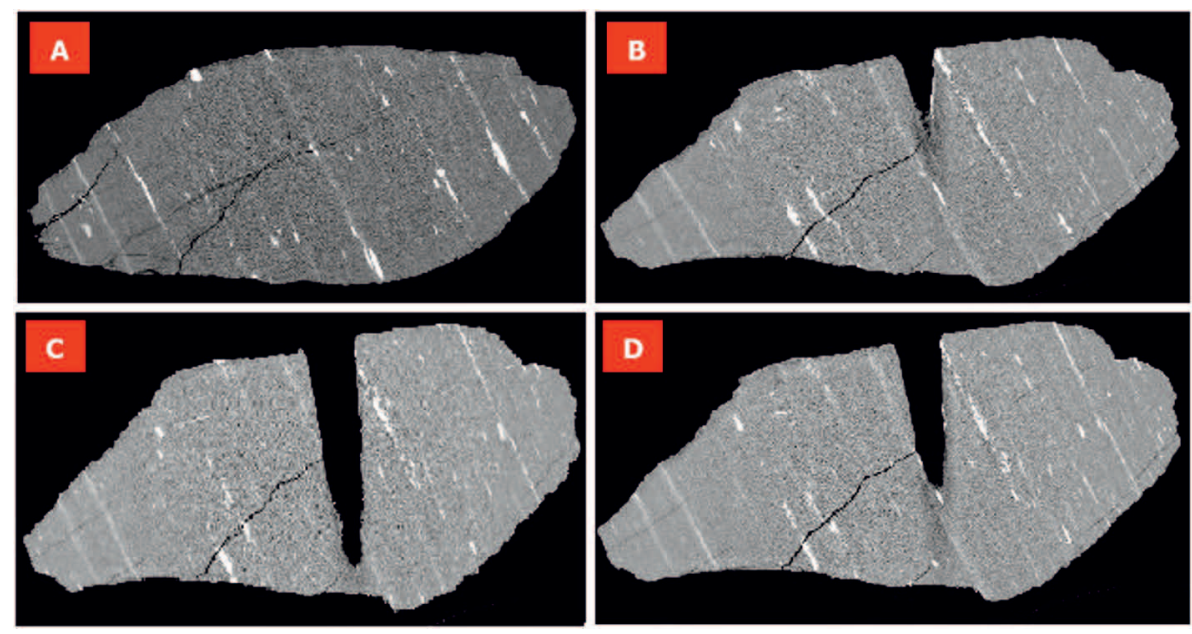

Rys. 4. Seria rentgenogramów z testu nr 1 . Wybrane obrazy cyfrowe bryły węgla zarejestrowane $\mathrm{w}$ interwałach co $5 \mathrm{~mm}$ wzdłuż osi $x$ 


\section{Test strzałowy drugi}

Do przeprowadzenia drugiego testu szczelinowania gazowego próbki węgla kamiennego zapewniono identyczne warunki techniczne jak w eksperymencie poprzednim. Próbkę węgla stabilizowano płaszczem cementowym, a ładunek propelantowy usytuowano centralnie w modelu badawczym poprzez pionowo nawiercony otwór, który posłużył również do przeprowadzenia linii balistycznej. Przygotowany do testu ładunek propelantowy charakteryzował się następującymi parametrami: waga $m=61,6 \mathrm{~g}$, wysokość $h=94,53 \mathrm{~mm}$, gę-

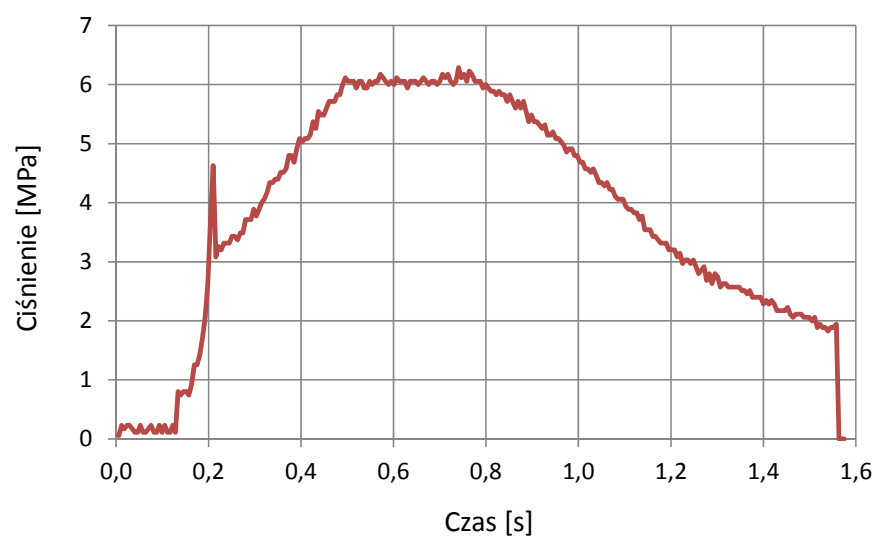

Rys. 5. Profil ciśnienia obrazujący dynamikę zjawiska spalania propelantu $\mathrm{w}$ teście szczelinowania gazowego próbki węgla $\mathrm{nr} 2$

stość $\rho=1,57 \mathrm{~g} / \mathrm{cm}^{3}$, objętość $V=39,2 \mathrm{~cm}^{3}$. Przebieg zmian ciśnieniowych zarejestrowanych $\mathrm{w}$ czasie trwania testu przedstawiono na rysunku 5 .

Podobnie jak to miało miejsce w poprzednim eksperymencie strzałowym, zarejestrowany pik początkowy ciśnienia $P_{z}^{(2)}=4,59 \mathrm{MPa}$ w momencie czasowym $t_{z}^{(2)}=0,21 \mathrm{~s}$ pochodzi od zainicjowania zapłonnika, którego zadaniem jest dalsze pobudzenie ładunku propelantowego. W przedziale czasowym $t_{\max }^{(2)}=<0,49-0,77 \mathrm{~s}>$ ciśnienie spalania propelantu chwilowo ustabilizowało się na stałym poziomie $\sim P_{\max }^{(2)}=6,1 \mathrm{MPa}$. Od tego momentu następuje łagodny spadek ciśnienia gazów w badanym układzie, aż do całkowitej jego relaksacji w chwili czasowej $t_{k o n}^{(2)}=1,59 \mathrm{~s}$, co spowodowane jest rozszczelnieniem modelu badawczego w wyniku zniszczenia płaszcza cementowego.

Wybrane rentgenogramy próbki węgla kamiennego, zeskanowanej tomografem komputerowym po ukończeniu testu szczelinowania gazowego $\mathrm{nr} 2$, przedstawiono na rysunku 6 .

Efektem próby strzałowej na modelu betonowo-stalowym jest powstanie dwóch szczelin w badanej bryle węgla kamiennego. Obie szczeliny zlokalizowane są w górnej części bryły i rozciągają się ukośnie ku dołowi. Zasięg pierwszej szczeliny nie przekracza $6,2 \mathrm{~cm}$. Szczelina druga mierzy $12,1 \mathrm{~cm}$. Zarejestrowane zmiany gęstości badanej próbki węglowej wyrażone w stopniach Hounsfielda (HU) przedstawiały się następująco: dla calizny bryły - 127 $\div 199$ (HU),
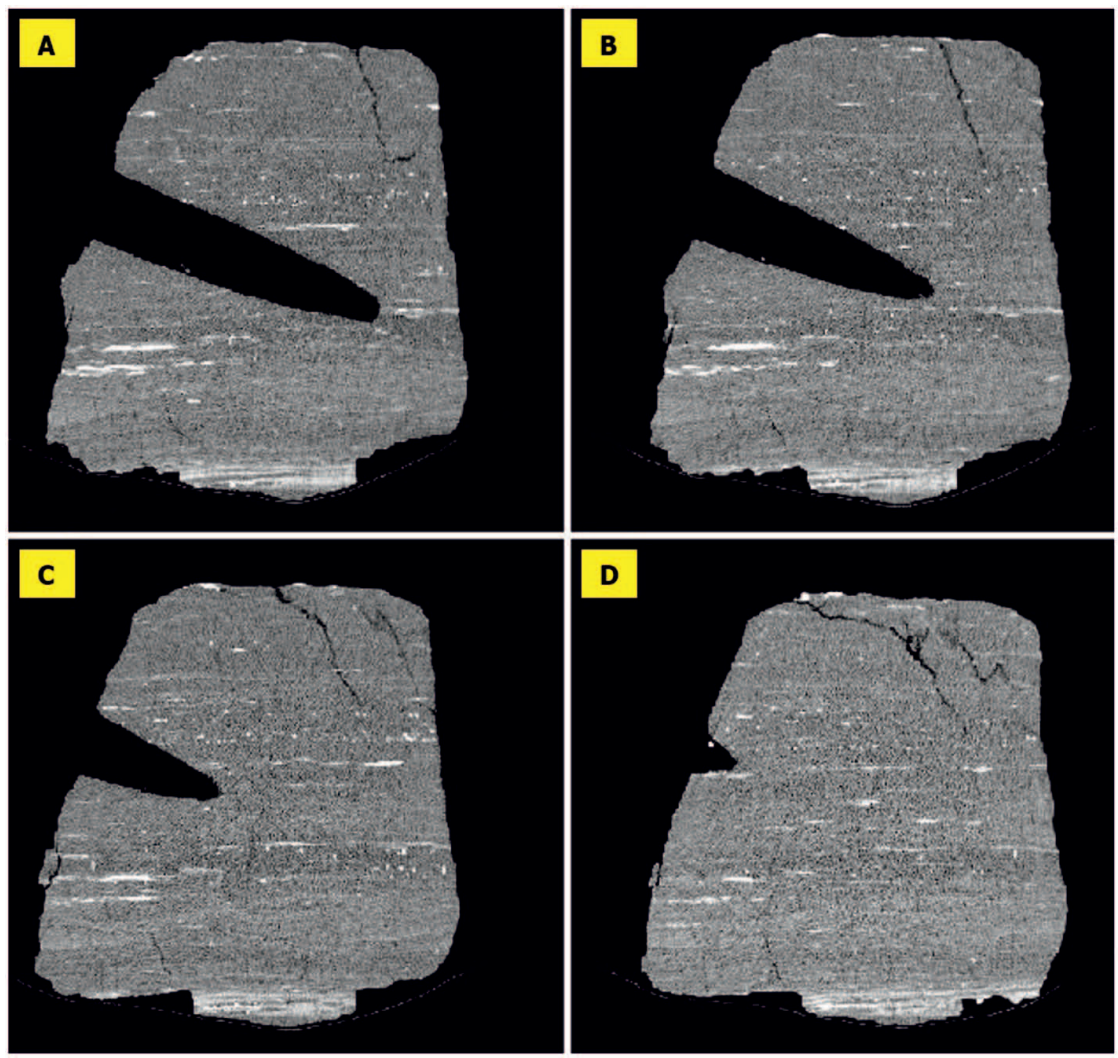

Rys. 6. Wybrane rentgenogramy próbki węgla kamiennego po ukończeniu testu strzałowego $\mathrm{nr} 2$. Na rysunek składa się sekwencja obrazów cyfrowych zarejestrowanych w interwałach co $5 \mathrm{~mm}$ wzdłuż osi $x$ dla obszaru spękań -201 do -30 (HU).

\section{Test strzałowy trzeci}

Eksperyment trzeci był ostatnim z zaplanowanych testów strzałowych i zamykał serię badań na poligonie. Analogicznie do dwóch poprzednich testów badaną bryłę węgla kamiennego zatopiono w płaszczu cementowym. Model strzałowy uzbrojono w ładunek propelantowy o wadze 62,2 g. Wolną przestrzeń $\mathrm{w}$ modelu wypełniono wodą i szczelnie zamknięto głowicą wyposażoną w króciec pomiarowy i przejście prądowe. Profil zmian ciśnieniowych w eksperymencie strzałowym $\mathrm{nr} 3$, zarejestrowany za pomocą czujnika piezorezystancyjnego umieszczonego w głowicy modelu strzałowego, przedstawiono na rysunku 7.

Profil ciśnienia w eksperymencie trzecim również otwiera pik zapłonnika $P_{z}^{3)}=1,69 \mathrm{MPa}$ $\mathrm{W}$ momencie czasowym $t_{z}^{(3)}=0,11 \mathrm{~s}-$ pochodzi on od zainicjowania zapłonnika, który w dalszej kolejności pobudza do zapłonu właściwy ładunek propelantowy. Po cza- 
sie $t_{\max }^{(3)}=1,35 \mathrm{~s}$ ciśnienie spalania propelantu osiąga wartość maksymalną, równą $P_{\max }^{(3)}=5,53 \mathrm{MPa}$. Od tej chwili ciśnienie zaczyna przybierać niższe wartości, by nagle spaść do poziomu bliskiego zeru w momencie czasowym $t_{\text {kon }}^{(3)}=1,52 \mathrm{~s}$. Zakończeniu testu strzałowego towarzyszyła nieoczekiwana fragmentacja części betonowej modelu badawczego.

Na rysunku 8 prezentowane są rentgenogramy próbki węgla kamiennego nr 3 ukazujące stan spękania bryły wskutek poddania jej działaniu ładunku propelantowego. Każdy z rysunków jest sekwencją obrazów cyfrowych pokazanych w interwałach odpowiednio wzdłuż osi $x$.

Efekt szczelinowania gazowego testu strzałowego $\mathrm{nr} 3$ odbiega od rezultatów obserwowanych w dwóch poprzednich eksperymentach. Analiza rentgenogramów pozwala stwierdzić występowanie wielu drobniejszych szczelin o mniejszej rozwartości niż zarejestrowane w testach 1 i 2 . Znaczna ilość szczelin układa się prostopadle do osi kanału centralnego, w którym umieszczony był ładunek propelantowy, nieliczne powstają w płaszczyźnie do nich prostopadłej, rozciągając się z pionie bryły. Wspólnym mianownikiem wszystkich przeprowadzonych testów jest zbliżony poziom stopni Hounsfielda (HU) odczytany dla calizny bryły w przedziale $113 \div 251$ (HU) i dla obszaru spękań -220 do -50 (HU).

Rys. 8. Seria rentgenogramów z testu nr 3. Wybrane obrazy cyfrowe próbki węgla po teście szczelinowania przedstawiające przekroje poprzeczne bryły w odległościach równych $10 \mathrm{~mm}$ wzdłuż osi $\mathrm{x}$

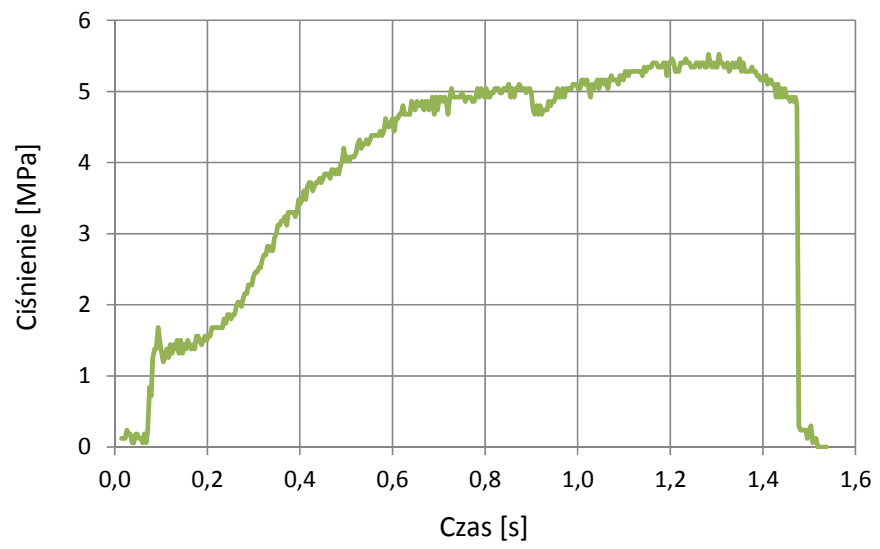

Rys. 7. Profil ciśnienia obrazujący dynamikę zjawiska spalania propelantu w teście szczelinowania gazowego próbki węgla nr 3
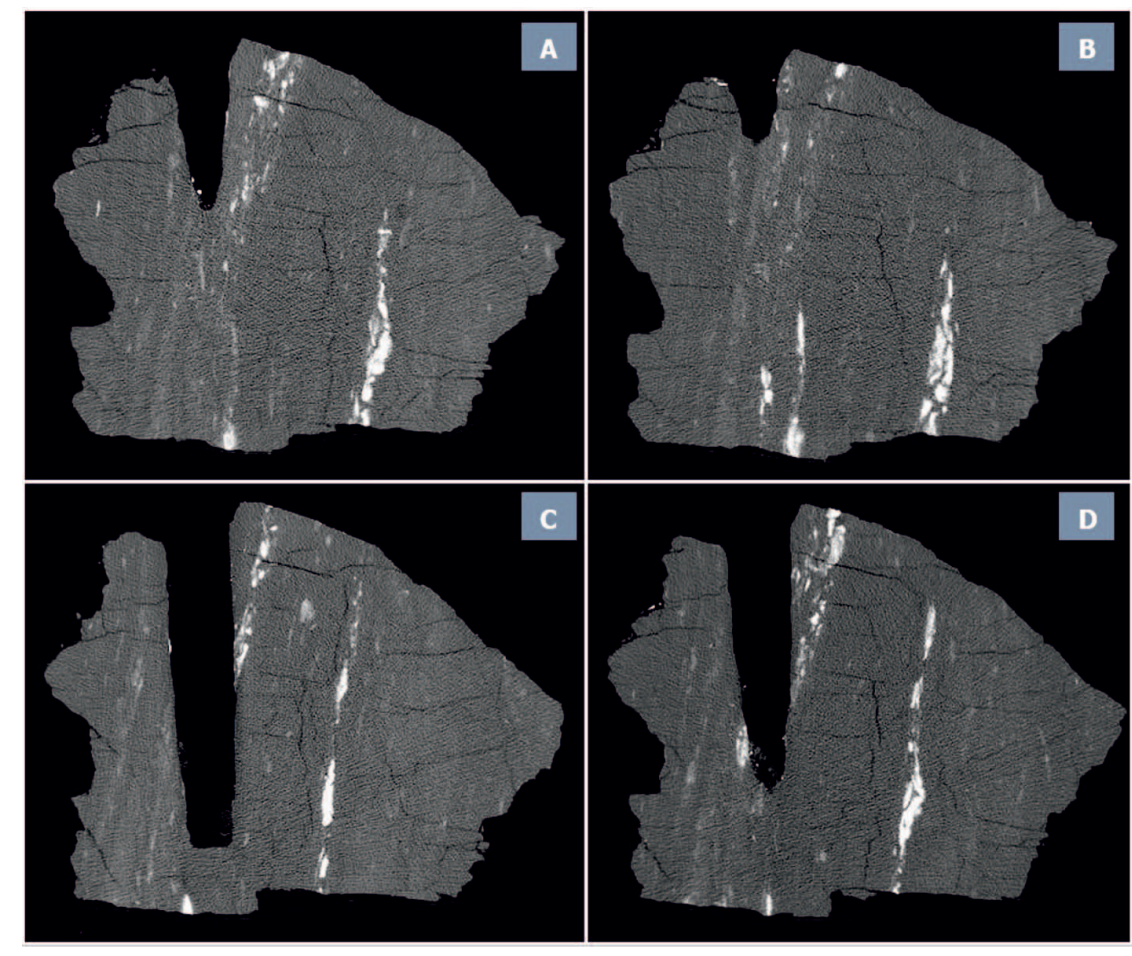

\section{Podsumowanie i wnioski}

1. Zaproponowano metodę badawczą polegającą na wizualnej ocenie spękań próbki węgla kamiennego wywołanych odpaleniem ładunku propelantowego w warunkach poligonowych. Próbki węgla po zabiegu szczelinowania gazowego zostały poddane wstępnym oględzinom natychmiast po wykonaniu testu strzałowego, a następnie dokonano oceny spękań na podstawie rentgenogramów pochodzących ze skanowania tomografem komputerowym. Dla każdego z testów wykreślono profil ciśnienia na podstawie danych pomiarowych uzyskanych za pomocą układu mierzącego i rejestrującego przebieg zmian ciśnieniowych.

2. Opracowano i wykonano układ badawczy, w którym próbkę węgla kamiennego z wywierconym otworem na ładu- nek propelantowy umieszczano w plastikowym naczyniu o pojemności 65 litrów i zalewano betonem. Po wysezonowaniu płaszcza betonowego układ pełnił rolę stabilizacyjną i przeciwdziałał całkowitej fragmentacji badanych brył węglowych. Przygotowano próbki węgla poprzez nawiercenie otworów, w których umieszczono ładunki propelantowe. Kanały wykonano wiertłem rdzeniowym o średnicy $35 \mathrm{~mm}$, głębokości zaś zamykały się w przedziale 150 $\div 190$ mm, w zależności od grubości bryły.

3. Przygotowano ładunki propelantowe do testów strzałowych. Badania strzałowe zrealizowano przy użyciu ładunków propelantowych składających się z mieszanki rodzimych paliw prochowych typu Szafir i Szmaragd. Ła- 
dunki prochowe otrzymały finalny cylindryczny kształt na skutek matrycowego zaprasowania pod prasą hydrauliczną. W górnej części ładunku nawiercono otwór, w którym umieszczono zapłonnik elektryczny. Całość zabezpieczono pod względem wodoszczelności płaszczem termokurczliwym.

4. Przeprowadzono serię prób szczelinowania gazowego próbek węgla kamiennego ładunkami propelantowymi przy zachowaniu warunków badania zbliżonych do rzeczywistych. Prace z użyciem materiałów wysokoenergetycznych prowadzono na poligonie strzałowym w specjalnie zaprojektowanych i wykonanych stanowiskach betonowo-stalowych.

5. Wykonano skanowania próbek węgla kamiennego poddanych działaniu ładunków propelantowych. Z uwagi na trudności w jednoznacznej ocenie wielkości i charakteru uzyskanych spękań wyłącznie na podstawie oględzin wizualnych próbki, posiłkowano się tomografią rentgenow- ską, dzięki której uzyskano obrazy cyfrowe próbek węgla poddanych oddziaływaniu ładunków propelantowych.

6. Rezultatem testów strzałowych na modelach betonowo-stalowych jest uzyskanie serii spękań brył węgla kamiennego poddanych szczelinowaniu gazowemu w warunkach zbliżonych do rzeczywistych. W dwóch pierwszych testach zaobserwowano powstanie wyraźnych, choć pojedynczych szczelin o rozciągłości od 6,2 do $12,7 \mathrm{~cm}$ i rozwartości nieprzekraczającej $0,45 \mathrm{~mm}$. Efektem trzeciej próby strzałowej jest uzyskanie wielu drobniejszych szczelin o mniejszych zasięgach i rozwartościach. Z uwagi na fakt, iż warunki eksperymentu były takie same dla wszystkich testów, a badany materiał węglowy pochodził z jednej kopalni (z tego samego pokładu węglowego), wytłumaczenie i uzasadnienie odmiennego charakteru spękań jest obecnie niemożliwe. Z pewnością pomocne w tym względzie będą wyniki dalszych prac, które są kontynuowane na szerszej grupie paliw prochowych.

Prosimy cytować jako: Nafta-Gaz 2016, nr 12, s. 1063-1068, DOI: 10.18668/NG.2016.12.08

Artykuł nadesłano do Redakcji 2.11.2016 r. Zatwierdzono do druku 25.11.2016 r.

Przedstawione w artykule badania zostały zrealizowane w ramach projektu badawczego GasDrain (RFCR-CT-2014-00004 WP 2, zadanie 2.2) współfinansowanego przez Komisję Europejską oraz Ministerstwo Nauki i Szkolnictwa Wyższego.

\section{Literatura}

[1] Brzóska K.: Gęstość węla kamiennego. W: Wybrane zagadnienia z fizykochemii węgla kamiennego, pod redakcją G. Ceglarskiej-Stefańskiej. Uczelniane Wydawnictwo Naukowo-Dydaktyczne, Kraków 2003, s. 7-53.

[2] Ceglarska-Stefańska G.: Fizykochemiczne czynniki wptywajace na proces sorpcji/desorpcji CH4 z węgli kamiennych. Wydawnictwo AGH, Kraków 2000, s. 179-200.

[3] Ceglarska-Stefańska G., Nodzeński A., Hołda S.: Badania uktadu wegiel-gaz $w$ aspekcie pozyskiwania metanu i sekwestracji $\mathrm{CO}_{2}$. Wydawnictwo IGSMiE PAN, Kraków 2007, t. 23, z. 3, s. $51-59$.

[4] Czerw K., Ceglarska-Stefańska G.: Dynamika deponowania gazów kopalnianych w strukturze porowatej węgla kamiennego. Gospodarka Surowcami Mineralnymi 2008, t. 24, z. 3/3, s. $57-67$.

[5] Gonet A., Nagy S., Rybicki C., Siemek J., Stryczek S., Wiśniowski R.: Technologia wydobycia metanu z pokładów węgla (CBM). Górnictwo i Geologia 2010, tom 5, zeszyt 3, s. $5-25$.

[6] Habera Ł.: Badania zapłonu propelantów na stacjonarnym silniku laboratoryjnym. Nafta-Gaz 2014, nr 11, s. 778-783.

[7] Hadro J., Wójcik I.: Metan pokładów węgla - zasoby i eksploatacja. Przegląd Geologiczny 2013, vol. 61, s. 404-410.

[8] Kędzior S., Hadro J., Kwarciński J., Nagy S., Młynarczyk M., Rostkowski R., Zalewska E.: Warunki naturalne występowania i metody eksploatacji metanu pokładów wegla $w$ wybranych zagłębiach węglowych USA oraz możliwości rozwoju eksploatacji tego gazu w Polsce. Sprawozdanie z wyjazdu szkoleniowego do USA. Przegląd Geologiczny 2007, vol. 55 , s. $565-570$
[9] Koślik P., Habera Ł.: Badania poligonowe propelantów obciążonych materiałem podsadzkowym. Nafta-Gaz 2016, nr 5, s. 311-315, DOI: 10.18668/NG.2016.05.01.

[10] Krzystolik P., Skiba J.: Gospodarcze wykorzystanie metanu z poktadów węgla $w$ warunkach polskich. Polityka Energetyczna 2009, t. 12, z. 2/2, s. 319-332.

[11] Kwarciński J., Hadro J.: Metan pokładów węgla na obszarze Górnoślaskiego Zagłębia Węglowego. Przegląd Geologiczny 2008, vol. 56, s. 486-490.

[12] Szymczak K., Gawor T., Wolszakiewicz T.: Materiaty wysokoenergetyczne. Metodyka badań liniowej szybkości spalania statych paliw rakietowych. Tom I, Warszawa 2009, s. $107-116$.

[13] Wolszakiewicz T.: Badania balistyczne i wytrzymatościowe stałych paliw rakietowych $w$ aspekcie prawidłowości ich zapłonu oraz możliwości wystepowania sytuacji awaryjnych pracy silników rakietowych. Instytut Przemysłu Organicznego, Warszawa 2013.

[14] Żyła M.: Układ wegiel kamienny-metan w aspekcie desorpcji i oddziaływania metanu z gazów kopalnianych. Wydawnictwo AGH, Kraków 2000.

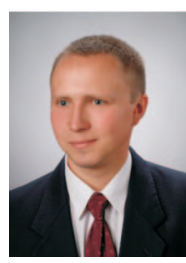

Dr inż. Łukasz HABERA

Adiunkt w Zakładzie Techniki Strzelniczej.

Instytut Nafty i Gazu - Państwowy Instytut Badawczy

ul. Lubicz 25 A

31-503 Kraków

E-mail: lukasz.habera@inig.pl 